\title{
Hydrogen-rich medium alleviates high glucose-induced oxidative stress and parthanatos in rat Schwann cells in vitro
}

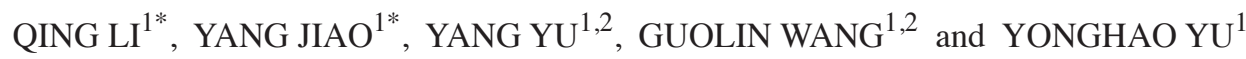 \\ ${ }^{1}$ Department of Anesthesiology, Tianjin Medical University General Hospital; \\ ${ }^{2}$ Anesthesiology Research Institute of Tianjin, Tianjin 300052, P.R. China
}

Received April 22, 2018; Accepted October 2, 2018

DOI: $10.3892 / \mathrm{mmr} .2018 .9631$

\begin{abstract}
Diabetic peripheral neuropathy (DPN) is considered to be the most common cause of microvascular diabetic complications, for which no effective therapies currently exist. Previous studies have identified that oxidative stress is the common pathway in all possible hypotheses for the induction of DPN, and poly(ADP-ribose) (PAR) polymerase-1 (PARP-1)-dependent cell death (parthanatos) is key in the pathogenic mechanisms of neurodegenerative disease. The aim of the present study was to investigate the protective effects and corresponding mechanisms of hydrogen-rich medium (HM) on high glucose (HG)-induced oxidative stress and parthanatos in primary rat Schwann cells (RSCs) in vitro. The RSCs were divided into groups and treated for $48 \mathrm{~h}$. Cell counting kit- 8 and lactate dehydrogenase assays were used to detect cell viability and cytotoxicity, respectively; intracellular $\mathrm{OH}^{-}$levels were measured using a DCFH-DA assay; concentrations of peroxynitrite $\left(\mathrm{ONOO}^{-}\right)$and 8 -hydroxy deoxyguanosine (8-OHdG) were evaluated with an enzyme-linked immunosorbent assay; relative expression levels of parthanatos-related proteins [PAR, nucleus apoptosis-inducing factor (AIF) and total AIF] were analyzed using western blot analysis, and immunofluorescence was used to determine the nuclear
\end{abstract}

Correspondence to: Professor Yonghao Yu or Dr Yang Yu, Department of Anesthesiology, Tianjin Medical University General Hospital, 154 Anshan Road, Heping, Tianjin 300052, P.R. China E-mail: yuyonghao@126.com

E-mail: sevenyu1987@outlook.com

${ }^{*}$ Contributed equally

Abbreviations: DPN, diabetic peripheral neuropathy; parthanatos, poly(ADP-ribose) polymerase-1-dependent cell death; ROS, reactive oxygen species; RNS, reactive nitrogen species; PARP-1, poly(ADP-ribose) polymerase-1; PAR, poly(ADP-ribose); AIF, apoptosis-inducing factor; $\mathrm{OH}^{-}$, cytotoxic hydroxyl; $\mathrm{ONOO}^{-}$, peroxynitrite; $\mathrm{HG}$, high glucose; HM, hydrogen-rich medium; RSC, rat Schwann cell

Key words: diabetic peripheral neuropathy, parthanatos, oxidative stress, hydrogen, Schwann cells translocation of AIF. After $48 \mathrm{~h}, \mathrm{HG}$ was shown to induce severe oxidative stress and promote marked levels of parthanatos in the RSCs. Treatment with HM inhibited HG-induced oxidative stress by reducing the production of $\mathrm{OH}^{-}$and $\mathrm{ONOO}^{-}$ and suppressed parthanatos by downregulating the levels of 8-OHdG, the expression of PAR and the nuclear translocation of AIF. HM improved cell viability and inhibited cytotoxicity under the HG condition. These results indicate that HM effectively reduces HG-induced oxidative stress in RSCs and protects them against parthanatos. Therefore, HM may be a novel treatment for DPN.

\section{Introduction}

With an aging population worldwide, the number of patients with diabetes is increasing each year globally (1). Diabetic peripheral neuropathy (DPN), which affects up to $50 \%$ of patients with diabetes mellitus (2), is considered to be one of the most common and dangerous microvascular diabetic complications, for which no effective therapy currently exists (3). Although the exact pathogenesis of DPN is complicated and remains to be fully elucidated, it is known that there are four main pathways involved in DPN: Polyol, advanced glycation end products, protein kinase $C$, and hexosamine pathways (4). However, Brownlee (5) indicated that oxidative stress induced by hyperglycemia can cause peripheral nervous injury through all of these pathways. A number of studies have indicated that suppressing the production of reactive oxygen species (ROS) and/or reactive nitrogen species (RNS) or attenuation of their detrimental effects may be a promising strategy for the treatment of DPN (5-7).

Parthanatos, also known as poly(ADP-ribose) (PAR) polymerase-1 (PARP-1)-dependent cell death, is a particular type of programmed cell death that is different from traditional apoptosis, necrosis and autophagy (8). Unlike apoptosis, parthanatos neither forms apoptotic bodies nor causes small DNA fragments. Unlike necrosis and authophagy, it does not trigger cell swelling or lysosomal degradation (9). As it cannot be rescued by a pan-caspase inhibitor (z-VAD-fmk), it is also a type of caspase-independent apoptosis (10). PARP-1, as a nuclear enzyme in DNA repair, is a risk factor for the progression of parthanatos $(6,11)$. Excessive DNA breakage triggered by excessive ROS/RNS production can rapidly activate PARP-1 and result in energy depletion. Notably, the 
superfluous activation of PARP-1 can also lead to the nucleus releasing a large number of PAR fragments into the cytoplasm, and can translocate apoptosis-inducing factor (AIF), which is another key factor, from the mitochondria to the nucleus in order to induce parthanatos (12). In previous years, numerous studies have identified that parthanatos is involved in the pathogenic mechanisms of neurodegenerative disease, stroke, ischemic reperfusion injury and diabetes mellitus (6,13-15), therefore, it may be a novel target for the treatment of these diseases.

Molecular hydrogen $\left(\mathrm{H}_{2}\right)$, as a selective antioxidant, can readily penetrate cell membranes, rapidly diffuse into the nucleus and mitochondria, and selectively neutralize the more cytotoxic hydroxyl $\left(\mathrm{OH}^{-}\right)$and peroxynitrite $\left(\mathrm{ONOO}^{-}\right)$ compared with traditional oxidation inhibitors (16). It is widely accepted that the inhalation of hydrogen gas or consumption of hydrogen-rich saline can protect against multiple diseases, including type 2 diabetes (11), neurodegenerative diseases (17), multiple organ dysfunction syndrome (18), sepsis and atherosclerosis (19). Our previous experimental studies have shown that $\mathrm{H}_{2}$ or $\mathrm{H}_{2}$-rich saline exhibit protective effects against sepsis, lung injuries, auditory neuropathy, brain injury and the early stage of DPN $(11,17,20-22)$.

In the present study, high glucose ( $\mathrm{HG} ; 50 \mathrm{mM})$ was used to treat primary rat Schwann cells (RSCs) as an in vitro cellular model of DPN, in order to investigate whether $\mathrm{H}_{2}$-rich medium (HM) treatment alleviates HG-induced injury and to elucidate the corresponding mechanisms.

\section{Materials and methods}

HM preparation. HM was prepared as previously described (11). Briefly, $\mathrm{H}_{2}$ (1 1//min) mixed with air $(1 \mathrm{l} / \mathrm{min})$ was dissolved in low glucose (5.6 mM of glucose) Dulbecco's modified Eagle's medium (DMEM; Gibco; Thermo Fisher Scientific, Inc., Waltham, MA, USA) for $4 \mathrm{~h}$ in order to reach supersaturation $\left(0.6 \mathrm{mM}\right.$ of $\left.\mathrm{H}_{2}\right)$ under the pressure conditions of $0.4 \mathrm{MPa} . \mathrm{H}_{2}$ was produced by a $\mathrm{GCH}-300$ high-purity hydrogen generator (Tianjin Tongpu Analytic Instrument Technology Co., Ltd., Tianjin, China). A sealed aluminum bag (no dead volume remaining) was used to store the saturated $\mathrm{HM}$ under the atmospheric conditions at $4^{\circ} \mathrm{C}$. In order to ensure the saturated concentration of $\mathrm{H}_{2}$, fresh $\mathrm{HM}$ was prepared every week.

RSC culture and treatment. The primary RSCs (cat. no. R1700) were cultured in low-glucose DMEM with 5\% fetal bovine serum (cat. no. 0025), 1\% Schwann cell growth supplement (cat. no. 1752) and 1\% penicillin/streptomycin solution (cat. no. 0503 ). The cells and growth media components were from ScienCell Research Laboratories, Inc. (San Diego, CA, USA) in a humid atmosphere of $5 \% \mathrm{CO}_{2}$ at $37^{\circ} \mathrm{C}$. When the cells reached $80 \%$ confluence, $0.05 \%$ trypsin-EDTA was added in order to produce the subsequent generation. The second and third generations of cells were selected for the subsequent experiments.

The RSCs were randomly divided into four groups and were treated for $48 \mathrm{~h}$ as follows: i) Primary low-glucose DMEM as the control group (Control); ii) saturated HM as the $\mathrm{H}_{2}$ group $\left(\mathrm{H}_{2}\right) ; 44.4 \mathrm{mM}$ of glucose with primary low-glucose
DMEM (50 mM of glucose in complete DMEM) as the HG group; and HG DMEM with saturated $\mathrm{H}_{2}$ as the treatment group $\left(\mathrm{HG}+\mathrm{H}_{2}\right)$.

Cell viability assay. Cell viability was detected using Cell Counting Kit-8 (CCK-8) assays (Dojindo Molecular Technologies, Inc., Kumamoto, Japan). Briefly, following pretreatment with $10 \mu \mathrm{M} \mathrm{z-VAD-fmk} \mathrm{(a} \mathrm{pan-caspase} \mathrm{inhibitor,}$ Selleckchem, Houston, TX, US) for $1 \mathrm{~h}$, the cells were seeded at a density of $2 \times 10^{3}$ cells per well in 96-well plates under the different conditions for $48 \mathrm{~h}$ at $37^{\circ} \mathrm{C}$, and 5 parallel wells were used for each group. Subsequently, $10 \mu \mathrm{l}$ of the kit reagent was added to each well and the cells were incubated at $37^{\circ} \mathrm{C}$ for a further $3 \mathrm{~h}$. A microplate reader (Molecular Devices LLC, Sunnyvale, CA, USA) was used to determine the cell density by measuring the absorbance at $450 \mathrm{~nm}$. Cell viability was calculated as the percentage cytoprotection compared with the control group, which was set at $100 \%$.

Lactate dehydrogenase $(L D H)$ assay. Cytotoxicity was determined using an LDH-cytotoxicity assay kit (BioVision, Inc., Milpitas, CA, USA). According to the manufacturer's protocol. Following pretreatment with z-VAD-fmk, all cells were divided into the following groups: Background control (200 $\mu 1$ assay medium without cells); low control (200 $\mu$ l assay medium with $2 \times 10^{4}$ cells/well); high control (200 $\mu$ l assay medium containing $1 \%$ Triton $\mathrm{X}-100$ with $2 \times 10^{4}$ cells/well); and test samples. All cells were incubated at $5 \% \mathrm{CO}_{2}, 90 \%$ humidity and $37^{\circ} \mathrm{C}$ for $48 \mathrm{~h}$. Subsequently, $100 \mu \mathrm{l}$ supernatant per well was carefully transferred into the corresponding wells of an optically clear 96-well plate. A total of $100 \mu 1$ reaction mixture was added to each well and the plate was incubated for up to $30 \mathrm{~min}$ at room temperature in the dark. A microplate reader was used to measure the absorbance of all samples at $490 \mathrm{~nm}$. Cytotoxicity (LDH release rate) was calculated according to the following formula: Cytotoxicity $(\%)=($ test sample-low control $) /($ high control-low control) $\mathrm{x} 100$.

DCFH-DA assay. Intracellular $\mathrm{OH}^{-}$levels were detected using a DCFH-DA assay (Beyotime Institute of Biotechnology, Jiangsu, China). All cells were pretreated with z-VAD-fmk. Briefly, following $48 \mathrm{~h}$ of treatment in the different groups, the cells were harvested at a concentration of $2 \times 10^{6}$ cells $/ \mathrm{ml}$ and labeled with DCFH-DA $(10 \mu \mathrm{M})$ in a humid atmosphere of $5 \% \mathrm{CO}_{2}$, shielded from light, for $20 \mathrm{~min}$. Subsequently, all labeled cells were washed and collected. Flow cytometry (BD Biosciences, Franklin Lakes, NJ, USA) was performed in order to detect the fluorescence intensity. The $\mathrm{OH}^{-}$level was determined as the percentage of labeled (DCFH-DA) to gated cells.

Enzyme-linked immunosorbent assay (ELISA). The levels of 8-hydroxy deoxyguanosine (8-OHdG), a type of DNA damage marker, and $\mathrm{ONOO}^{-}$were measured using the Highly Sensitive 8-OHdG Check ELISA kit (Japan Institute for the Control of Aging, Shizuoka, Japan) and ONOO- ELISA kit (Yueyan Bio, Shanghai, China), respectively. All cells were pretreated with z-VAD-fmk and then treated under the different conditions for $48 \mathrm{~h}$. The supernatant of the samples was obtained by 

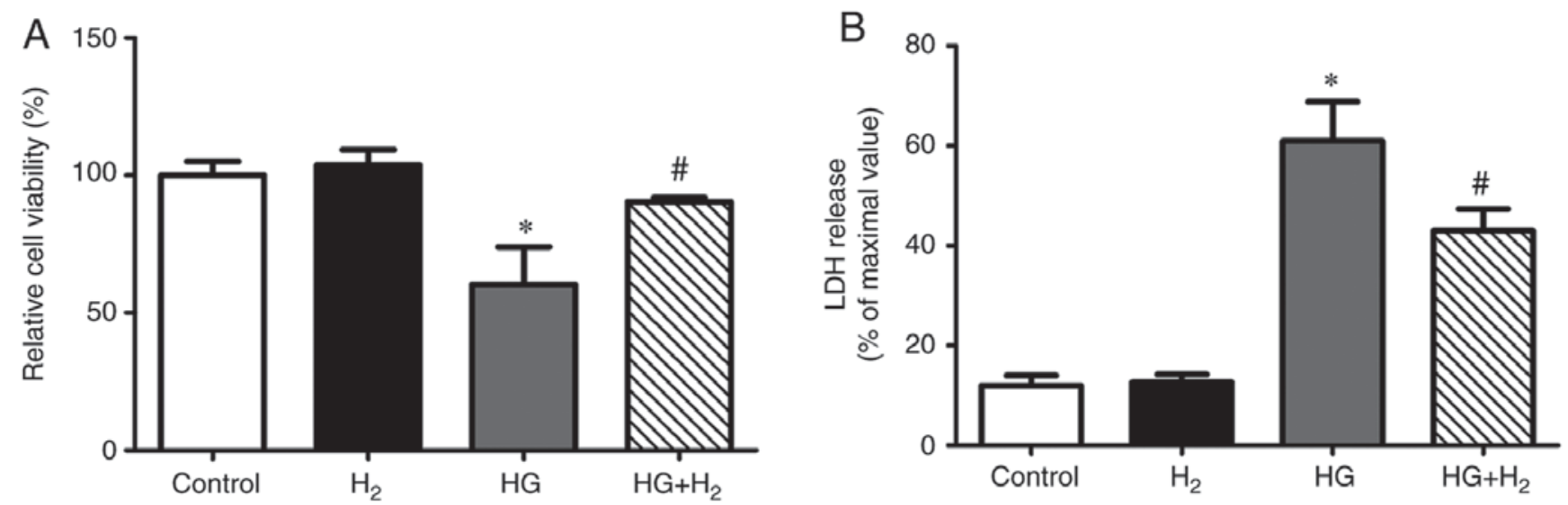

Figure 1. Results of the CCK-8 and LDH assays. Following treatment for $48 \mathrm{~h}$, a (A) CCK-8 assay was used to examine cell viability and an (B) LDH assay was used to determine cytotoxicity. The results are presented as the mean \pm standard deviation ( $\mathrm{n}=5 /$ group). ${ }^{*} \mathrm{P}<0.05$, vs. control group; ${ }^{*} \mathrm{P}<0.05$, vs. HG group. CCK-8, Cell Counting Kit-8; LDH, lactate dehydrogenase; HG, high glucose.

centrifugation at $2,000 \mathrm{x}$ g for $15 \mathrm{~min}$ at $4^{\circ} \mathrm{C}$, and the levels of 8 -OHdG and $\mathrm{ONOO}^{-}$were evaluated according to the manufacturer's protocol.

Extraction of nucleoprotein. An NE-PER Nuclear and Cytoplasmic Extraction kit (Thermo Fisher Scientific, Inc.) was used to extract the nucleoprotein of the RSCs. All cells were harvested with trypsin-EDTA and then centrifuged at $500 \mathrm{x}$ g for $5 \mathrm{~min}$ at $4^{\circ} \mathrm{C}$. The cell pellet was suspended in PBS and then $1 \times 10^{6}$ cells were transferred to a $1.5-\mathrm{ml}$ microcentrifuge tube. The cells were pelleted by centrifugation at $500 \mathrm{x} \mathrm{g}$ for $3 \mathrm{~min}$ at $4^{\circ} \mathrm{C}$. A pipette was used to carefully remove and discard the supernatant, following which ice-cold CER I was added to the cell pellet. Subsequently, the nuclear protein was extracted according to the manufacturer's protocol.

Western blot analysis. Western blot analysis was used to measure the relative expression levels of parthanatos-associated proteins. Following $48 \mathrm{~h}$ of treatment, the cells were lysed using RIPA buffer (Beijing Solarbio Science \& Technology Co., Ltd., Beijing, China) and the lysates were quantified using the BCA Protein Assay Kit (Thermo Fisher Scientific, Inc.). Equal amounts $(50 \mu \mathrm{g})$ of protein samples were separated with $10 \%$ SDS-PAGE. The electrophoretic bands were transferred onto PVDF membranes (EMD Millipore, Billerica, MA, USA), which were blocked with $5 \%$ fat-free milk for $2 \mathrm{~h}$. Subsequently, the membranes were incubated with antibodies against AIF (1:1,000; rabbit polyclonal; cat. no. ab1998; Abcam, Cambridge, MA, USA), PAR (1:1,000; rabbit polyclonal; cat. no. 4336-BPC-100; Trevigen; Bio-Techne, Minneapolis, MN, USA) and $\beta$-actin (1:2,000; cat. no. A5060; Sigma-Aldrich; Merck KGaA, Darmstadt, Germany) at $4^{\circ} \mathrm{C}$ with mild consistent agitation overnight. The immunoblots were washed with TBST three times (10 min per wash) and incubated with 1:5,000 diluted goat-anti-rabbit IgG (cat. no. 05557; Sigma-Aldrich; Merck $\mathrm{KGaA}$ ) for $2 \mathrm{~h}$ at room temperature. The membranes were then washed with TBST three times (10 min per wash), following which an image analysis system (Bio-Rad Laboratories, Inc., Hercules, CA, USA) was used to scan the membranes and a Gel-pro analyzer (Media Cybernetics, Inc., Rockville, MD, USA) was used to determine the integrated optical density.
Immunofluorescence. Following $48 \mathrm{~h}$ of treatment, immunofluorescence was used to measure the translocation of AIF. The cells were washed three times ( 5 min per wash) with PBS and were then treated as follows: $80 \%$ alcohol and absolute ethyl alcohol were used to fix the samples for $30 \mathrm{~min}$ at $-20^{\circ} \mathrm{C}$ under rotation; $0.5 \%$ Triton-100 was used to penetrate the cells for $10 \mathrm{~min}$; and 10\% donkey serum (Amyjet Scientific, Wuhan, China) was used to block the samples for $1 \mathrm{~h}$ at room temperature. Subsequently, anti-AIF (cat. no. ab1998; rabbit polyclonal; Abcam) was added to the cells at a dilution of 1:1,000 and then they were incubated at $4^{\circ} \mathrm{C}$ overnight. The following day, the cells were recovered for $30 \mathrm{~min}$ and then were incubated with 1:100 goat anti-rabbit IgG/TRITC (OriGene Technologies, Inc., Beijing, China) for $1 \mathrm{~h}$ at room temperature in the dark. The samples were stained with 4',6-diamidino-2-phenylindole (DAPI) for $1 \mathrm{~min}$, following which the cells were washed and mounted. Images were captured with a fluorescence microscope (Leica Microsystems GmbH, Wetzlar, Germany). At least three images of each group were captured.

Statistical analysis. Data are presented as the mean \pm standard deviation. Depending on whether the distribution was Gaussian or not, an unpaired t-test or Mann-Whitney test, respectively, was used to analyze the differences between the control and $\mathrm{HG}$ groups, and the $\mathrm{HG}+\mathrm{H}_{2}$ and $\mathrm{HG}$ groups. One-way analysis of variance was used to analyze the interaction among all groups. $\mathrm{P}<0.05$ was considered to indicate a statistically significant difference, and the significance testing was two-tailed. Statistical analysis was performed using GraphPad Prism (version 5.0; GraphPad Software, Inc., La Jolla, CA, USA) and SPSS (version 21.0; IBM Corp., Armonk, NY USA) software.

\section{Results}

$H M$ exerts protective effects against $H G$-induced cell death in RSCs. In order to investigate the effects of HM on cellular viability and cytotoxicity, the RSCs were assessed using CCK-8 (Fig. 1A) and LDH (Fig. 1B) assays, respectively, following treatment in different groups for $48 \mathrm{~h}$. Compared with the control group, the viability of the RSCs exposed 

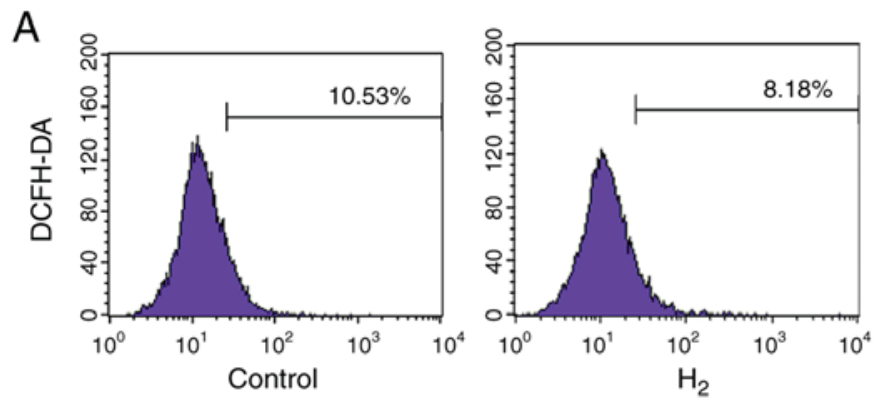

B

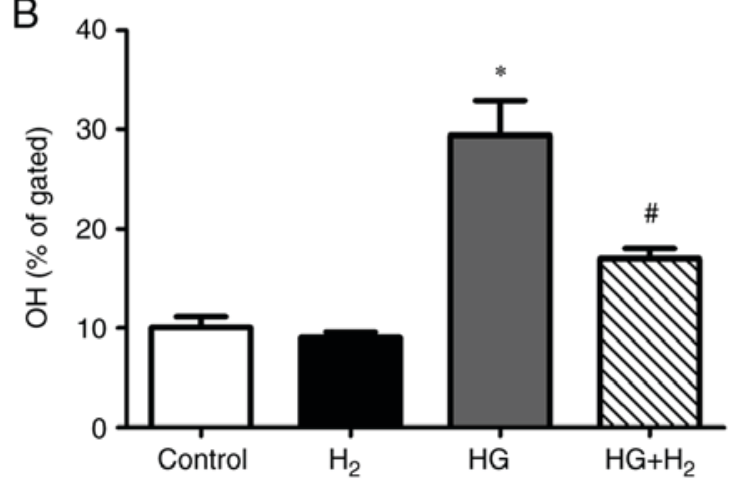

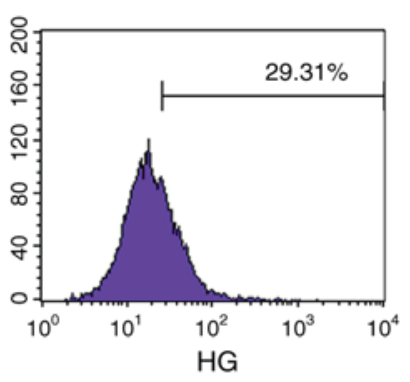

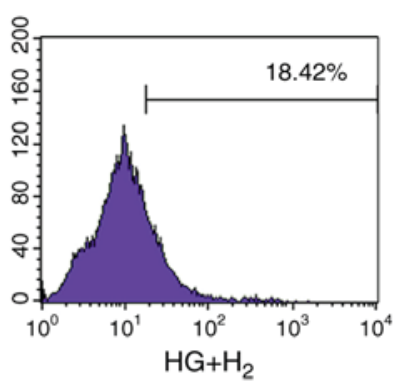

C

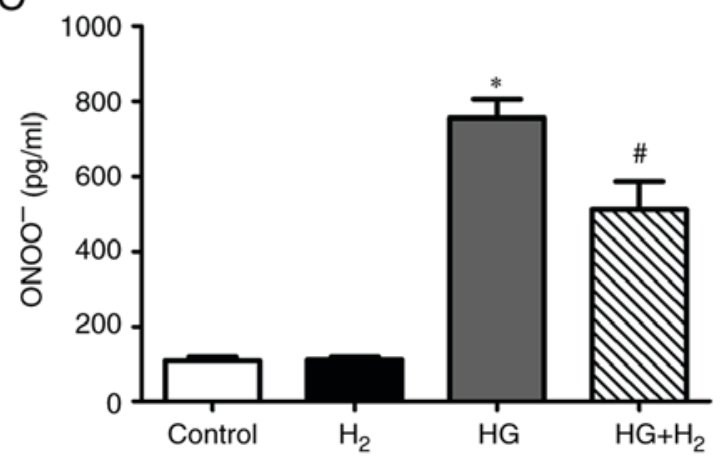

Figure 2. Levels of intracellular $\mathrm{OH}^{-}$and $\mathrm{ONOO}^{-}$. A DCFH-DA assay and an enzyme-linked immunosorbent assay were used to detect the levels of intracellular $\mathrm{OH}^{-}$and $\mathrm{ONOO}^{-}$, respectively. (A) Images of the flow cytometry. A total of 20,000 cells per group were collected following treatment for 48 h. Quantitative analysis of $(\mathrm{B}) \mathrm{OH}^{-}$and $(\mathrm{C}) \mathrm{ONOO}^{-}$. Data are presented as the mean \pm standard deviation (n=3/group). ${ }^{*} \mathrm{P}<0.05$, vs. control group; ${ }^{\#} \mathrm{P}<0.05$, vs. $\mathrm{HG}$ group. $\mathrm{OH}{ }^{\text {, }}$ cytotoxic hydroxyl; ONOO-, peroxynitrite; $\mathrm{HG}$, high glucose.

to $\mathrm{HG}$ was significantly lower $(64.46 \pm 3.13 \%$ of the control, $\mathrm{n}=5, \mathrm{P}<0.05)$ and cytotoxicity was significantly enhanced $(61.40 \pm 2.94 \%, \mathrm{n}=5, \mathrm{P}<0.05)$. HM improved the cell viability $(84.29 \pm 1.19 \%$ of the control, $\mathrm{n}=5, \mathrm{P}<0.05)$ and inhibited the cytotoxicity $(42.80 \pm 2.32 \%, \mathrm{n}=5, \mathrm{P}<0.05)$ under $\mathrm{HG}$.

$H M$ reduces $\mathrm{HG}$-induced production of $\mathrm{OH}^{-}$and $\mathrm{ONOO}^{-}$in $R S C s$. The levels of intracellular $\mathrm{OH}^{-}$(a type of ROS) and $\mathrm{ONOO}^{-}$(a type of RNS) in the different groups were detected using a DCFH-DA assay and ELISA, respectively. Compared with the control group, the relative levels of intracellular $\mathrm{OH}^{-}$(Fig. 2A and B) and $\mathrm{ONOO}^{-}$(Fig. 2C) were significantly enhanced in the $\mathrm{HG}$ group $\left(\mathrm{OH}^{-}, 30.89 \pm 3.87 \%, \mathrm{n}=3, \mathrm{P}<0.05\right.$; ONOO- $\left.^{-}, 764.23 \pm 48.72 \mathrm{pg} / \mathrm{ml}, \mathrm{n}=3, \mathrm{P}<0.05\right)$. HM depressed the levels of $\mathrm{OH}^{-}$and $\mathrm{ONOO}^{-}$in the $\mathrm{HG}+\mathrm{H}_{2}$ group in comparison with those in the $\mathrm{HG}$ group $\left(\mathrm{OH}^{-}, 18.33 \pm 1.0 \%, \mathrm{n}=3, \mathrm{P}<0.05\right.$; $\left.\mathrm{ONOO}^{-}, 553.11 \pm 38.65 \mathrm{pg} / \mathrm{ml}, \mathrm{n}=3, \mathrm{P}<0.05\right)$.

HM mitigates the generation of $8-O H d G$ in RSCs under $H G$ conditions. HG treatment markedly increased the levels of $8-\mathrm{OHdG}$, a sensitive DNA damage biomarker induced by ROS/RNS, compared with that in the control group $(1,177.37 \pm 60.97$ pg/ml, n=3, P<0.05; Fig. 3). However, HM treatment efficiently reduced the generation of $8-\mathrm{OHdG}$ under HG conditions $(732.05 \pm 54.28 \mathrm{pg} / \mathrm{ml}, \mathrm{n}=3, \mathrm{P}<0.05)$.

HM has inhibitory effects on parthanatos in RSCs. Western blot analysis was used to analyze the expression of parthanatos-associated proteins (Fig. 4A). The relative optical density of PAR/ $\beta$-actin was used to determine the expression of PAR, and the nuclear translocation of AIF was calculated as the ratio of nuclear AIF to total AIF. The expression levels

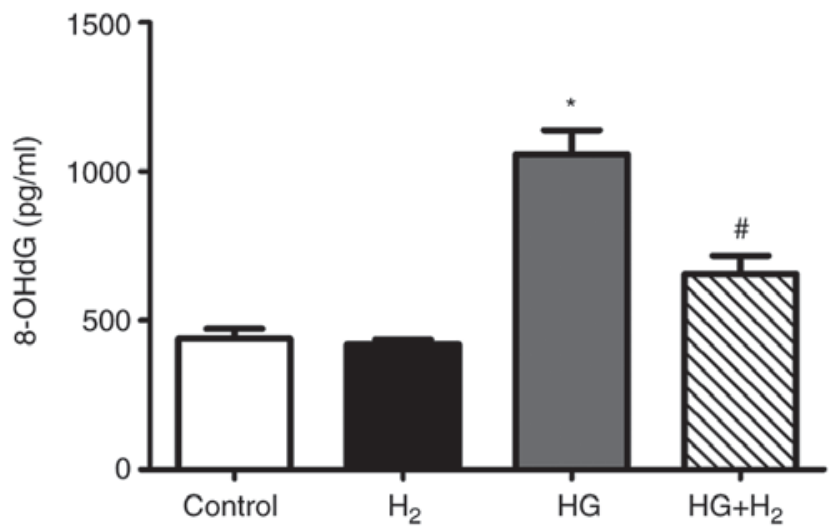

Figure 3. Results of the 8-OHdG generation analysis. An enzyme-linked immunosorbent assay was used to determine the levels of 8-OHdG (a DNA damage biomarker) following treatment for $48 \mathrm{~h}$. Data are presented as the mean \pm standard deviation ( $\mathrm{n}=3 /$ group). ${ }^{*} \mathrm{P}<0.05$, vs. control group; ${ }^{*} \mathrm{P}<0.05$, vs. HG group. OHdG, 8-hydroxy deoxyguanosine; HG, high glucose.

of PAR (Fig. 4B) and nuclear translocation of AIF (Fig. 4C) were markedly increased in the HG group compared with the control group (PAR/ $\beta$-actin, 0.66 $\pm 0.06, \mathrm{n}=3, \mathrm{P}<0.05$; nuclear AIF/total AIF, $0.52 \pm 0.03, \mathrm{n}=3, \mathrm{P}<0.05)$. Treatment with $\mathrm{HM}$ significantly reduced the expression levels of PAR and the nuclear translocation of AIF compared with the HG group (PAR/ $\beta$-actin, 0.48 $\pm 0.02, \mathrm{n}=3, \mathrm{P}<0.05$; nuclear AIF/total AIF, $0.38 \pm 0.03, \mathrm{n}=3, \mathrm{P}<0.05)$.

HM suppresses the HG-induced nuclear translocation of $A I F$. Immunofluorescence was used to detect the intracellular distribution of AIF (Fig. 5). AIF was stained with TRITC (red) 
A
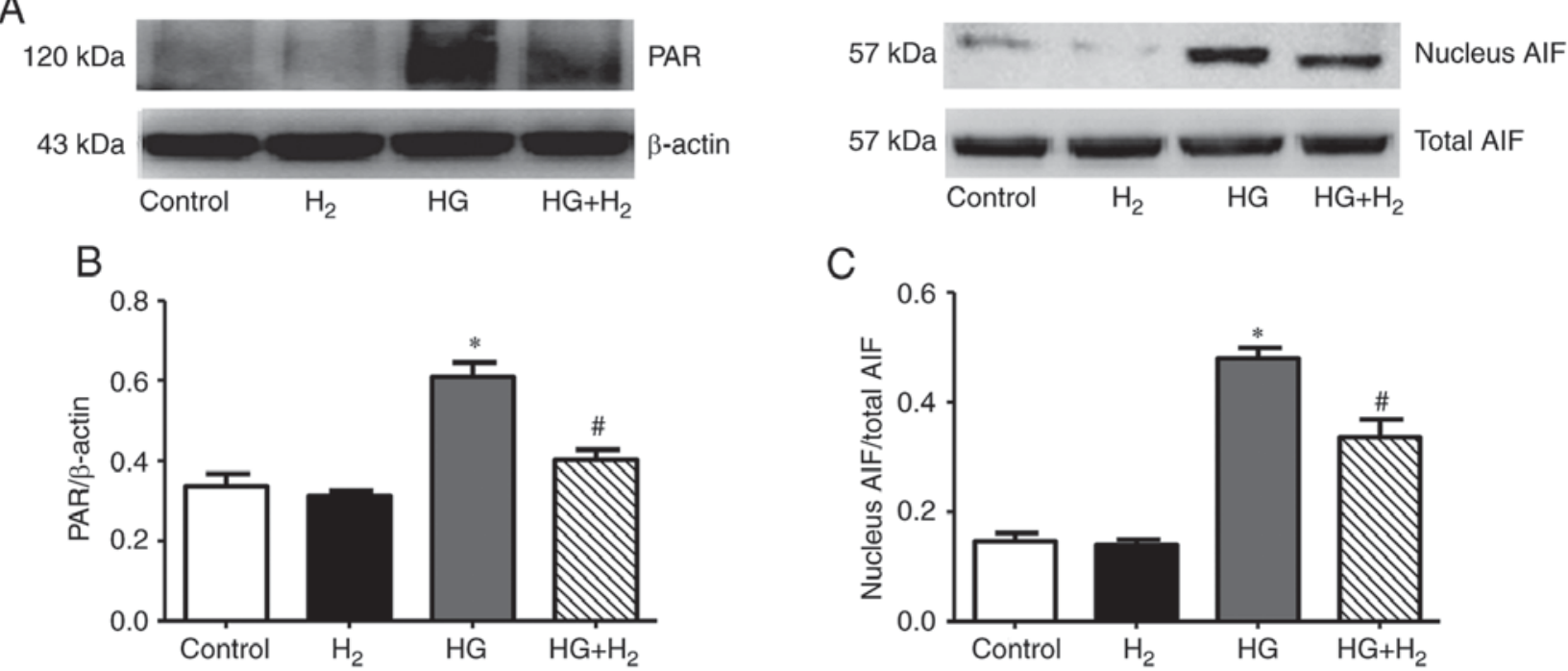

Figure 4. Relative expression of parthanatos-related proteins. Following treatment for $48 \mathrm{~h}$, western blot analysis was performed. (A) Expression of PAR, $\beta$-actin, nuclear AIF and total AIF. Quantitative analysis of the (B) expression of PAR (PAR/ $\beta$-actin) and the (C) nuclear translocation of AIF (nuclear AIF/total AIF). Data are expressed as the mean \pm standard deviation ( $\mathrm{n}=3$ /group). ${ }^{*} \mathrm{P}<0.05$, vs. control group; ${ }^{*} \mathrm{P}<0.05$, vs. HG group. Parthanatos, poly(ADP-ribose) polymerase-1-dependent cell death; PAR, poly(ADP-ribose); AIF, apoptosis-inducing factor; HG, high glucose.
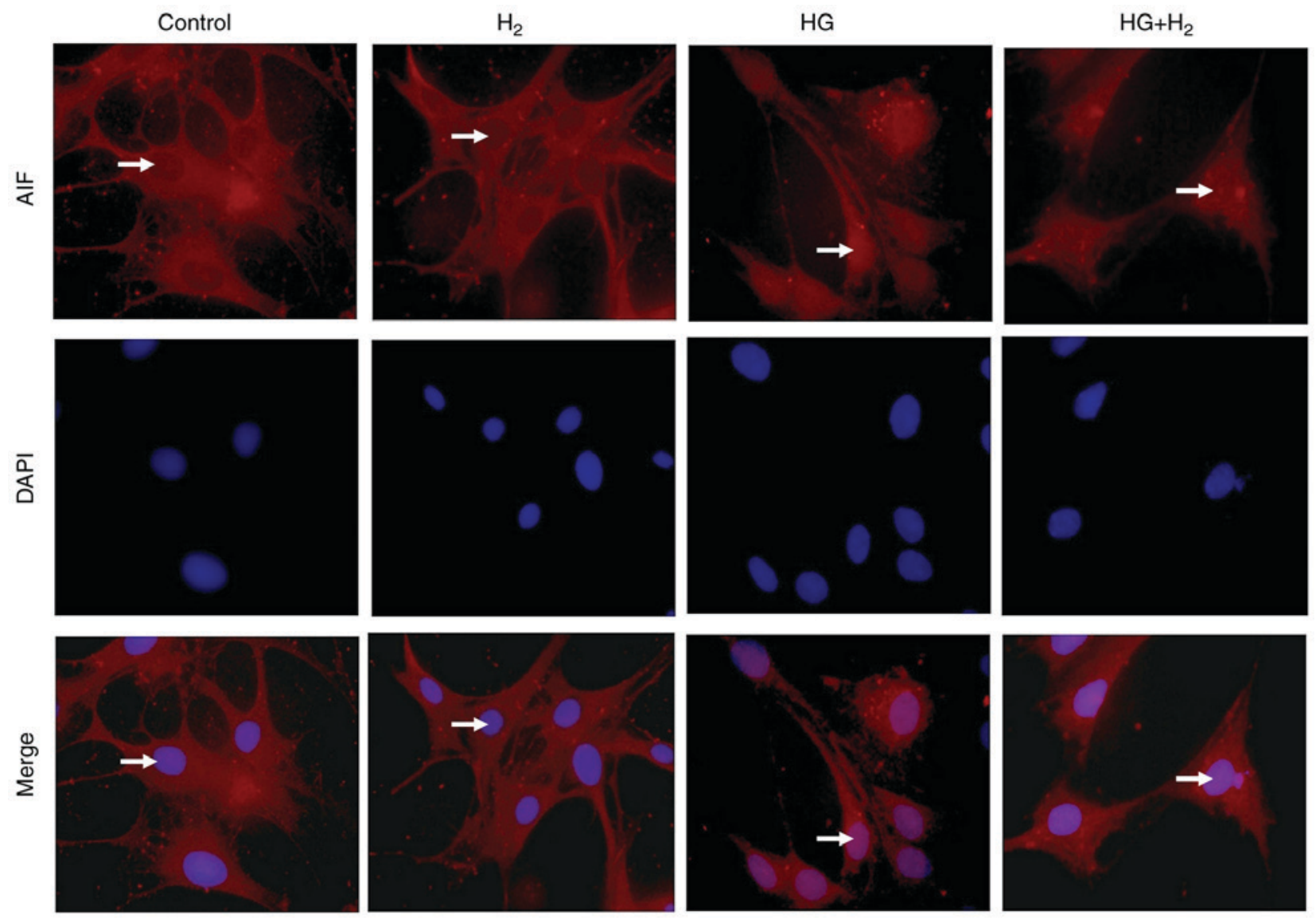

Figure 5. Results of analysis of the nuclear translocation of AIF. Immunofluorescence was used to detect the intracellular distribution of AIF (indicated by the white arrows) following treatment for $48 \mathrm{~h}$. Original magnification, $\mathrm{x} 1,000$. The exposure time was $0.5 \mathrm{sec}$ for AIF and $0.1 \mathrm{sec}$ for DAPI. AIF was stained with TRITC (red) and nuclei were stained using DAPI (blue). AIF, apoptosis-inducing factor; DAPI, 4',6-diamidino-2-phenylindole; HG, high glucose.

and the nucleus was stained using DAPI (blue). In the normal cells, the red fluorescence was present in the cytoplasm but not the nucleus. Following treatment with HG for 48 h, the red fluorescence was distributed throughout the cell and was particularly present in the nucleus. In the $\mathrm{HG}+\mathrm{H}_{2}$ group, the red fluorescence was distributed only in a small region of the 
nucleus and mainly in the cytoplasm. These results indicated that HG induces AIF to translocate from the cytoplasm into the nucleus and that HM may suppress this process.

\section{Discussion}

Schwann cells, as a type of glial and myelin-forming cell, are widely used in in vitro studies of peripheral nervous system diseases (23). Previous studies have shown that injury of Schwann cells can cause peripheral nerve damage, including segmental demyelination (one of the characteristic changes of DPN), a reduction in nerve conduction velocity, acceleration of axonal atrophy and inhibition of nerve repair (24), which all result in the occurrence of DPN (25). As Schwann cells absorb glucose through an insulin-independent pathway, they are more sensitive to hyperglycemia and more susceptible to attack by HG (26). It is widely recognized that hyperglycemia, which occurs in all patients with diabetes mellitus, is the main reason for diabetic complications (5). As damage to Schwann cells is reversible (24), Schwann cells may be a target in the treatment of DPN. Therefore, HG $(50 \mathrm{mM})$ was used to treat RSCs for $48 \mathrm{~h}$ in order to induce an in vitro model of DPN in the present study. In our previous study, RSCs were treated with $44.4 \mathrm{mM}$ mannitol in addition to DMEM, as it has the same osmotic pressure as $50 \mathrm{mM} \mathrm{HG}$, which excluded the influence of any osmotic changes caused by HG treatment The results demonstrated no significant differences in various measurements between the control and mannitol groups. Therefore, HG, but not a high osmotic pressure, induces injury of Schwann cells (11).

PARP-1, as the most abundant protein in the PARP family, is considered to be a key factor in the induction of parthanatos. As a DNA repair enzyme, PARP-1 can immediately respond to DNA damage, whether DNA single- or double-strand breaks, and promote DNA repair machinery via nicotinamide adenine dinucleotide $\left(\mathrm{NAD}^{+}\right)$-dependent poly(ADP-ribosyl) ation on histones or PARP-1 itself (10). However, the excessive activation of PARP-1 can also induce the nucleus to generate large numbers of PAR fragments and release them into the cytoplasm, which can promote the nuclear translocation of AIF from the mitochondria and trigger parthanatos. The superfluous activation of PARP-1 can also consume the store of $\mathrm{NAD}^{+}$, exhaust ATP, and destroy the integrity of the oxidative respiratory chain, which leads to cell death by caspase-3-induced necrosis or apoptosis (13). PARP-1 itself, as a substrate of caspase-3, can be decomposed from 116 $\mathrm{kDa}$ into 89 and $24 \mathrm{kDa}$ and lose its function (12). In order to prevent the disturbance of caspase- 3 in the present study, z-VAD-fmk, an irreversible broad-spectrum inhibitor of the caspase family, was used to pretreat all cells. The results in RSCs indicated that HG (50 mM) induced severe cell toxicity and significant peripheral neural system injury, which did not involve the caspase family as it was not traditional apoptosis or necrosis. This effect was markedly attenuated by treatment with saturated HM $(0.6 \mathrm{mM})$ for $48 \mathrm{~h}$. The present study also demonstrated that treatment with $50 \mathrm{mM} \mathrm{HG}$ for $48 \mathrm{~h}$ increased the levels of DNA damage, and activated PARP-1, PAR fragments and the nuclear translocation of AIF, which all lead to parthanatos. However, this type of cell death process was inhibited by treatment with HM. No statistically significant difference was observed between the control and HM groups, thus $\mathrm{H}_{2}$ gas did not induce damage of the normal cells. Therefore, HM can protect RSCs from HG-induced parthanatos in vitro.

Oxidative stress is considered to be an imbalance between the production of ROS and/or RNS and activated anti-oxidative mechanisms in cells (18). According to a previous study, DNA damage caused by oxidative stress is the largest driver for the activation of PARP-1 (27). Oxidative stress is considered to be the common pathway in all possible hypotheses for the induction of DPN. The overproduction of ROS/RNS, including superoxide anions $\left(\mathrm{O}^{-}\right), \mathrm{OH}^{-}$, nitric oxide $(\mathrm{NO})$ and $\mathrm{ONOO}^{-}$, leads to varying degrees of dysfunction and damage in the peripheral nervous system (28). Among all free radicals, $\mathrm{OH}^{-}$and $\mathrm{ONOO}^{-}$are considered to be the most toxic and destructive (29). The excessive production of $\mathrm{ONOO}^{-}$can cause severe oxidative stress and lead to DNA breaks, which may activate PARP-1 and result in parthanatos (12). $\mathrm{H}_{2}$, as an antioxidant, can selectively neutralize the more harmful $\mathrm{ONOO}^{-}$and $\mathrm{OH}^{-}$, but has no effect on $\mathrm{NO}, \mathrm{O}^{-}$or other types of free radical (17). The present study demonstrated that HM reduced the generation of $\mathrm{ONOO}^{-}$and $\mathrm{OH}^{-}$induced by $\mathrm{HG}$ in RSCs and protected the cells against oxidative stress (11). HM also exerted protective effects against HG-induced parthanatos in the RSCs. Therefore, it was hypothesized that these inhibitory effects on parthanatos are caused by the selective depression of $\mathrm{ONOO}^{-}$and $\mathrm{OH}^{-}$; however, further investigations are required to verify this hypothesis.

In conclusion, HM effectively reduced the oxidative stress induced by HG in RSCs and protected them against parthanatos; therefore, HM may be a novel treatment for DPN.

\section{Acknowledgements}

Not applicable.

\section{Funding}

This study was supported by the National Natural Science Fund of China (grant no. 81671888), the Youth Incubating Fund of Tianjin Medical University General Hospital (grant no. ZYYFY2016036) and The Science and Technology Development Fund of Tianjin Education Commission for Higher Education (grant no. 2017KJ194).

\section{Availability of data and materials}

The datasets used or analyzed during the present study are available from the corresponding author on reasonable request.

\section{Authors' contributions}

YaY, YoY and GW conceived and designed the study. QL and YJ performed the experiments. YaY wrote the manuscript. GW and YoY reviewed and edited the manuscript. All authors read and approved the manuscript.

\section{Ethics approval and consent to participate}

Not applicable. 


\section{Patient consent for publication}

Not applicable.

\section{Competing interests}

The authors declare that they have no competing interests.

\section{References}

1. Hu C and Jia W: Diabetes in China: Epidemiology and genetic risk factors and their clinical utility in personalized medication Diabetes 67: 3-11, 2018.

2. Alam U, Riley DR, Jugdey RS, Azmi S, Rajbhandari S, D'Août K and Malik RA: Diabetic neuropathy and gait: A review. Diabetes Ther 8: 1253-1264, 2017.

3. Vinik AI, Camacho P, Reddy S, Valencia WM, Trence D, Matsumoto AM and Morley JE: Aging, diabetes, and falls. Endocr Pract 23: 1117-1139, 2017.

4. Kobayashi M and Zochodne DW: Diabetic neuropathy and the sensory neuron: New aspects of pathogenesis and their treatment implications. J Diabetes Investig, 2018.

5. Brownlee M: The pathobiology of diabetic complications, A unifying mechanism. Diabetes 54: 1615-1625, 2005.

6. Sun LQ, Zhao J, Zhang TT, Qu L, Wang X, Xue B, Li XJ, Mu YM and Lu JM: Protective effects of Salvianolic acid B on Schwann cells apoptosis induced by high glucose. Neurochem Res 37 996-1010, 2012.

7. Sifuentes-Franco S, Pacheco-Moisés FP, RodriguezCarrizalez AD and Miranda-Diaz AG: The role of oxidative stress, mitochondrial function, and autophagy in diabetic polyneuropathy. J Diabetes Res 2017: 1673081, 2017

8. Fatokun AA, Dawson VL and Dawson TM: Parthanatos: Mitochondrial-linked mechanisms and therapeutic opportunities. Br J Pharmacol 171: 2000-2016, 2014.

9. Cheng SY, Wang SC, Lei M, Wang Z and Xiong K: Regulatory role of calpain in neuronal death. Neural Regen Res 13: 556-562, 2018.

10. Huang CT, Huang DY, Hu CJ, Wu D and Lin WW: Energy adaptive response during parthanatos is enhanced by PD98059 and involves mitochondrial function but not autophagy induction. Biochim Biophys Acta 1843: 531-543, 2014.

11. Yu Y, Ma X, Yang T, Li B, Xie K, Liu D, Wang G and Yu Y: Protective effect of hydrogen-rich medium against high glucose-induced apoptosis of Schwann cells in vitro. Mol Med Rep 12: 3986-3992, 2015.

12. Bárány T, Simon A, Szabó G, Benkő R, Mezei Z, Molnár L, Becker D, Merkely B, Zima E and Horváth EM: Oxidative stress-related parthanatos of circulating mononuclear leukocytes in heart failure. Oxid Med Cell Longev 2017: 1249614, 2017.

13. Tajuddin N, Kim HY and Collins MA: PARP inhibition prevents Ethanol-induced neuroinflammatory signaling and neurodegeneration in rat adult-age brain slice cultures. J Pharmacol Exp Ther 365: 117-126, 2018.

14. Zille M, Karuppagounder SS, Chen Y, Gough PJ, Bertin J, Finger J, Milner TA, Jonas EA and Ratan RR: Neuronal death after hemorrhagic stroke in vitro and in vivo shares features of ferroptosis and necroptosis. Stroke 48: 1033-1043, 2017.
15. Zhao H, Ning J, Lemaire A, Koumpa FS, Sun JJ, Fung A, Gu J, Yi B, Lu K and Ma D: Necroptosis and parthanatos are involved in remote lung injury after receiving ischemic renal allografts in rats. Kidney Int 87: 738-748, 2015

16. Shimada S, Wakayama K, Fukai M, Shimamura T, Ishikawa T, Fukumori D, Shibata M, Yamashita K, Kimura T, Todo S, et al: Hydrogen gas ameliorates hepatic reperfusion injury after prolonged cold preservation in isolated perfused rat liver. Artif Organs 40: 1128-1136, 2016.

17. Yu Y, Yang Y, Bian Y, Li Y, Liu L, Zhang H, Xie K, Wang G and $\mathrm{Yu} \mathrm{Y}$ : Hydrogen gas protects against intestinal injury in wild type but not NRF2 knockout mice with severe sepsis by regulating HO-1 and HMGB1 release. Shock 48: 364-370, 2017.

18. Xie K, Liu L, Yu Y and Wang G: Hydrogen gas presents a promising therapeutic strategy for sepsis. Biomed Res Int 2014: 807635, 2014

19. Chen Y, Chen H, Xie K, Liu L, Li Y, Yu Y and Wang G: H2 treatment attenuated pain behavior and cytokine release through the HO-1/CO pathway in a rat model of neuropathic pain. Inflammation 38: 1835-1846, 2015

20. Li J, Dong Y, Chen H, Han H, Yu Y, Wang G, Zeng Y and Xie K: Protective effects of hydrogen-rich saline in a rat model of permanent focal cerebral ischemia via reducing oxidative stress and inflammatory cytokines. Brain Res 1486: 103-111, 2012.

21. Yang T, Wang L, Sun R, Chen H, Zhang H, Yu Y, Wang Y, Wang G, Yu Y and Xie K: Hydrogen-rich medium ameliorates lipopolysaccharide-induced barrier dysfunction via Rhoa-Mdial signaling in Caco-2 cells. Shock 45: 228-237, 2016.

22. Hong Y, Sun LI, Sun R, Chen H, Yu Y and Xie K: Combination therapy of molecular hydrogen and hyperoxia improves survival rate and organ damage in a zymosan-induced generalized inflammation model. Exp Ther Med 11: 2590-2596, 2016.

23. Xue B, Wang L, Zhang Z, Wang R, Xia XX, Han PP, Cao LJ, Liu YH and Sun LQ: Puerarin may protect against Schwann cell damage induced by glucose fluctuation. J Nat Med 71: 472-481, 2017.

24. Ko PY, Yang CC, Kuo YL, Su FC, Hsu TI, Tu YK and Jou IM Schwann-cell autophagy, functional recovery, and scar reduction after peripheral nerve repair. J Mol Neurosci 64: 601-610, 2018.

25. Rachana KS, Manu MS and Advirao GM: Insulin-induced upregulation of lipoprotein lipase in Schwann cells during diabetic peripheral neuropathy. Diabetes Metab Syndr 12: 525-530, 2018

26. Yao W, Yang X, Zhu J, Gao B, Liu R and Xu L: Tang-Luo-Ning, a traditional Chinese medicine, inhibits endoplasmic reticulum stress-induced apoptosis of Schwann cells under high glucose environment. Evid Based Complement Alternat Med 2017: $5193548,2017$.

27. Scott TL, Rangaswamy S, Wicker CA and Izumi T: Repair of oxidative DNA damage and cancer: Recent progress in DNA base excision repair. Antioxid Redox Signal 20: 708-726, 2014.

28. Román-Pintos LM, Villegas-Rivera G, Rodríguez-Carrizalez AD, Miranda-Díaz AG and Cardona-Muñoz EG: Diabetic polyneuropathy in type 2 Diabetes mellitus: Inflammation, oxidative stress, and mitochondrial function. J Diabetes Res 2016: 3425617 , 2016.

29. Li Y, Gorelik G, Strickland FM and Richardson BC: Oxidative stress, T cell DNA methylation, and lupus. Arthritis Rheumatol 66: 1574-1582, 2014.

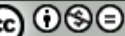

This work is licensed under a Creative Commons Attribution-NonCommercial-NoDerivatives 4.0 International (CC BY-NC-ND 4.0) License. 